\title{
CentRALIDADE dA EXPERIÊNCIA E DA RELAÇÃO SOCIAL PARA A COMPREENSÃO DO ENCONTRO INTER-RELIGIOSO NA REALIDADE BRASILEIRA
}

\author{
THE CENTRALITY OF EXPERIENCE AND SOCIAL RELATION \\ TO THE UNDERSTANDING OF THE INTER-RELIGIOUS ENCOUNTER
}

IN BRAZILIAN REALITY

\author{
Miguel MAHFOUD ${ }^{(*)}$ \\ YURI ELIAS GASPAR ${ }^{(\star *)}$
}

\begin{abstract}
RESUMO
Atualmente a convivência inter-religiosa é desafio central e urgente. Objetivamos nesse artigo discutir a importância da experiência (a partir de Giussani e da Fenomenologia) e da relação social (por meio da Abordagem Relacional) para compreender a constituição do encontro inter-religioso na realidade brasileira. As análises indicam que a experiência (juízo pessoal diante do vivido) é fator fundamental para compreender o encontro inter-religioso em sua unidade e diversidade. Enquanto experiência, o encontro inter-religioso é acontecimento que provoca os sujeitos envolvidos a elaborarem a própria posição diante da alteridade a partir do reconhecimento de um centro aberto e compartilhado. A cultura brasileira oferece um contexto facilitador de experiências de encontro inter-religioso baseadas no reconhecimento mútuo e na vivência profunda da própria religiosidade na relação com a alteridade. A compreensão do encontro inter-religioso enquanto relação social implica considerar os fatores intencionais e estruturais desse fenômeno. Trata-se de realidade emergente que forma os sujeitos envolvidos, e emerge como bem relacional que possibilita o reconhecimento da diferença e de um horizonte humano recíproco. A possibilidade da convivência salutar está mais em se dispor à provocação do encontro inter-religioso em sua complexidade característica do que em propor modelos abstratos para resolver os dramas da diferença.
\end{abstract}

Palavras-Chave: Experiência. Relação social. Encontro inter-religioso.

\begin{abstract}
Nowadays the inter-religious interaction is a central and urgent challenge. The present article aims to discuss the importance of experience (based on Giussani and on the Phenomenology) and of social relation (based on the Relational Approach) to the understanding of the inter-religious encounter constitution in Brazilian reality. The analysis indicates that the experience (personal judgment regarding life happenings) is an essential element to understand the inter-religious encounter in its unit and diversity. As experience, the inter-religious encounter is an occurrence that provokes the involved subjects to elaborate their own position facing otherness from the acknowledgement of an open and shared center. Brazilian culture offers a context that plays a role of facilitator of inter-religious encounter experiences based on mutual recognition and on the profound living of own religiosity in the relation with otherness. The understanding of the interreligious encounter as social relation implies the consideration of this phenomenon's intentional and structural factors. It means emergent reality that forms the involved subjects, and it emerges

${ }^{(*)}$ Doutor em Psicologia Social pelo Instituto de Psicologia da Universidade de São Paulo - USP. Pósdoutorado na Pontifícia Universidade Lateranense de Roma. Professor Associado efetivo na Universidade Federal de Minas Gerais - UFMG. Editor da revista Memorandum: memória e história em psicologia, Belo Horizonte. E-mail: mmahfoud@fafich.ufmg.br

(** ) Mestre em Psicologia pela Universidade Federal de Minas Gerais. Doutorando em Psicologia pela mesma instituição (bolsista CAPES). Editor Assistente da revista Memorandum: memória e história em Psicologia, Belo Horizonte. E-mail: yurieliasgaspar@yahoo.com.br
\end{abstract}


as a relational good that allows the recognition of the difference and of a reciprocal human horizon. The possibility of healthy interaction is more connected to the opening to the provocation of the inter-religious encounter in its characteristic complexity than to the proposal of abstract models to resolve the dramas of difference.

KEYWORDS: Experience. Social relation. Inter-religious encounter.

\section{INTRODUÇãO}

O encontro e a convivência com o diferente é um fato que perpassa a história da humanidade, especialmente do Brasil. Na atualidade, esta realidade se tornou estruturalmente presente. A pluralidade deixa de ser uma situação para se tornar $a$ condição característica do mundo de hoje: o mundo contemporâneo é mundo pluralizado, segundo Berger e Luckmann (2004). A globalização dos mercados, da tecnologia, da mídia e dos movimentos migratórios traz para o seio de cada sociedade múltiplas propostas culturais e religiosas, fazendo com que a coexistência com o diferente se torne questão de todos (ALES BELLO, 1998; DonATI, 2010, Hall, 2006; TOURAINE, 1999; SCOLA, 2008; WARNIER, 2003).

Se o encontro intercultural já é marcadamente provocador, a provocação do encontro inter-religioso é superlativa, parafraseando Sanchis (2008) ${ }^{1}$. O impacto tende a ser, por excelência, mais desafiador, e a diferença mais solicitadora, pois é o modo de apreensão da totalidade que está em jogo. Assim como o estranhamento, a negação, a dominação e o extermínio tendem a ser mais intensos, a surpresa, a admiração e o intercâmbio também (HALL, 2006; SANTOS, 2002; SOdRÉ, 2004 e 2005). O encontro inter-religioso revela então a sua potência, capaz de evidenciar uma possibilidade concreta fundamental de relacionamento com o diferente.

Como modelo cultural e político-institucional para a gestão da diversidade em sociedades multiétnicas, o multiculturalismo busca responder ao problema da convivência advertindo o respeito à dignidade de todas as modalidades expressivas humanas (SEMPRINI, 1999; SODRÉ, 2005). Entretanto, este modelo chegou a uma rápida falência por apoiar-se sobre as bases frágeis do relativismo cultural, que tende a dissolver a individualidade na identidade coletiva e a afirmar a absoluta alteridade e incomparabilidade das culturas, como se elas fossem totalmente autoreferentes (Di MARTINO, 2008; Donati, 2010; Esposito, 2008). Se os mundos histórico-culturais não podem ser comparados porque não há critério comum que fundamente sua avaliação, não há valor que ultrapasse sua mera fatualidade: a afirmação absoluta da diferença pode resultar na pura indiferença (AlEs Bello, 1998; Di MARTINo, 2008). O ideal implícito no relativismo cultural e, por

\footnotetext{
1 "Religião é cultura. Mas religião não se confunde simplesmente com cultura. É cultura no superlativo." (SANCHIS, 2008, p. 78).
} 
decorrência, no multiculturalismo é, portanto, a simples co-existência e tolerância entre culturas e religiões. Como efeito colateral da defesa da impossibilidade de comparação, emerge então a impossibilidade do relacionamento, restando apenas o caminho da estranheza, da hostilidade ou da subjugação, ainda que sob o controle de algum código de ética (Berger; Luckmann, 2004; Di Martino, 2008, Donati, 2010).

Ainda que outros modelos mais elaborados e inclusivos sejam propostos com o intuito de facilitar o caminho de construção de um diálogo que respeite a identidade, a dignidade e a liberdade humana (Donati, 2010; SEMPrini, 1999), queremos chamar a atenção para o fato de que não está somente no nível da construção de modelos (ainda que perfeitamente justos e plausíveis) o ponto-chave que permite superar as dificuldades do relacionamento inter-religioso. Elaborar um modelo mais adequado para a questão inter-religiosa é fundamental e necessário, mas não suficiente. O modelo suscita um "dever ser" que, não obstante abra caminhos, não tem a força, por si, de provocar a totalidade da caminhada. É preciso um olhar que apreenda outros elementos que se colocam em jogo quando a questão é a acolhida da diferença.

De fato, observando a realidade brasileira, apreendemos experiências concretas de relacionamento inter-religioso baseado contemporaneamente no reconhecimento (e enriquecimento) mútuo e na vivência profunda da própria religiosidade na relação com a alteridade. Provocados por essas evidências reais de relacionamentos, perguntamo-nos: qual a incidência de considerar o encontro inter-religioso enquanto fenômeno psicossocial fundamentado na experiência e na relação social? Estas situações de encontro inter-religioso seriam casuais ou são facilitadas pelo contexto sociocultural brasileiro? Nesse sentido, objetivamos no presente artigo discutir a importância da experiência (a partir das elaborações de Giussani e do referencial fenomenológico) e da relação social (por meio das contribuições apresentadas pela Abordagem Relacional) para a compreensão da constituição do encontro inter-religioso na realidade brasileira.

\section{A CENTRALIDADE DA EXPERIÊNCIA HUMANA NO RELACIONAMENTO INTER-RELIGIOSO}

No âmbito do relacionamento inter-religioso, vimos que a construção de modelos politicamente-corretos para enfrentar o drama da convivência tem se mostrado insuficiente. O problema não está na qualidade do modelo, mas na sua elevação ao status de critério para avaliar e construir a realidade social. É nesse sentido que, na esteira do pensamento de Giussani e da Fenomenologia Clássica de 
Husserl $(2006,2012)$ e Stein $(2003,2005)$, retomamos a radicalidade e o valor da experiência enquanto fonte originária do saber. É na experiência e por meio dela que podemos verificar a validade e a correspondência de cada modelo que nos é proposto, e não o contrário. Mas o que seria experiência? Quais são seus elementos constitutivos?

Estas são questões extensas e complexas que a Fenomenologia vem elaborando ao longo de seu desenvolvimento e não nos cabe aqui apresentá-las em todas as suas nuances ${ }^{2}$. O que nos interessa é retomar a experiência em seu caráter gnosiológico, evidenciando o seu dinamismo próprio e as conseqüências de sua consideração para o problema inter-religioso.

Em sua definição, experiência implica posicionamento do sujeito. Não há experiência sem elaboração do vivido. Podemos viver muitas situações e não fazer experiência delas, isto é, não tomá-las nas mãos (MAHFOUD, 2012). Experiência implica também juízo a partir de um critério pessoal, a um só tempo humano porque apresenta certo dinamismo compartilhado por todos - e pessoal - porque realizado numa história única, própria, dentro de um contexto que, num certo sentido, dá forma e concretude a esse critério. Nas palavras de Giussani (2009), há algo elementar que estrutura toda experiência:

Uma mãe esquimó, uma mãe da Terra do Fogo e uma mãe japonesa dão à luz seres humanos que são todos reconhecíveis como tais, seja pelos caracteres exteriores seja pela marca interior. Assim, quando eles disserem "eu", utilizarão essa palavra para indicar uma multiplicidade de elementos derivados de diversas histórias, tradições e circunstâncias. Mas, indubitavelmente, quando disserem "eu" usarão tal expressão também para indicar uma face interior, um “coração”, como diria a Bíblia, que é igual para cada um deles, embora traduzido das mais diversas maneiras (p. 26-7, grifos do autor).

Deste modo, Giussani (2009) identifica um ponto nuclear da experiência que possibilita o reconhecimento do outro como um ser humano, um "eu" com características próprias e com uma dignidade ineliminável. Tal constatação abre caminho para o relacionamento com o diferente em termos radicais, pois o que interessa é que cada tomada de posição - por mais diversa que seja - corresponda àquela dinâmica que mais nos caracteriza humanamente. Neste nível de experiência, pode haver efetivamente igualdade na diferença.

Em sua crítica à racionalidade ocidental tipicamente moderna, Husserl (2012) aponta o quanto a objetivação do sujeito reduz essa unidade e complexidade próprias da experiência. Tal objetivação não só desconsidera a experiência como

\footnotetext{
${ }^{2}$ Para uma discussão mais aprofundada, ver Mahfoud e Massimi (2008).
} 
possibilidade de conhecimento do real - por fragmentá-la e reduzi-la a algum dos fatores que a compõem - como também elimina a pessoa como sujeito da experiência - na medida em que esta só se torna apreensível a partir do método positivista, neutro e externo ao sujeito (GASPAR; MAHFOUD, 2006). A experiência se torna então fator de alienação: não se pode confiar naquilo que ela apresenta.

Qual a conseqüência imediata dessa consideração para o relacionamento interreligioso? Se a experiência não é mais fator que incide no modo de vivermos tais relações, passamos a avaliar aquilo que vivemos por critérios outros, que se reduzem fundamentalmente ao âmbito da ideologia, seja ela qual for. A experiência perde o seu caráter de solicitação pessoal, e o tom das relações passa a ser definido pelas normas de conduta abstratamente aplicadas pelos sujeitos envolvidos. Deste modo, as relações correm o risco de tornarem-se objetos de controle e manipulação (sejam moralmente boas ou não). Em síntese, não nos envolvemos pessoalmente com quem nos relacionamos. E sem um envolvimento pessoal, ainda que se considere a experiência, a mesma é tomada por um fator que, não obstante seja verdadeiro, tende a ser afirmado de modo exclusivo e totalitário.

Muitas vezes, ancorando-se numa perspectiva empirista, se reduz a experiência ao nível das sensações e emoções, e o critério norteador do sujeito passa a ser os impulsos, tendências e/ou sentimentos que ele carrega (GIUSSANI, 2009; MAHFOUD; MASSIMI, 2008). Tal configuração agrava os dramas do relacionamento interreligioso, já que as diferenças (e proximidades) passam a ser lidas não pelo critério de verdade (que implica elaboração e posicionamento do sujeito), mas por aquilo que reativamente lhe impacta. Não interessa a provocação que o outro é, mas sim se esta tem a ver com o próprio gosto pessoal.

Ainda numa perspectiva empirista, pode-se reduzir a experiência à sua manifestação exterior, isto é, ao comportamento (GIUSSANI, 2009; MAHFOUD; MASSIMI, 2008). Neste nível, o relacionamento entre pessoas de religiões diferentes pode se tornar representação de papéis de como deveria se configurar tal relação, esvaziando-a da implicação pessoal. Assim, diferenças ou proximidades podem ser exaltadas sem mesmo estarem presentes no vivo da relação.

Outras vezes, numa perspectiva racionalista, a experiência é tomada somente como elaboração mental, desvinculando-se da realidade imediata de onde ela nasceu (GIUSSANI, 2009; MAHFOUd; MASSIMI, 2008). O relacionamento passa então a ser ocasião de reafirmação de discursos e jogos de poder. Isso é evidente e dramático quando a questão refere-se ao tema religioso, pois se perde a pessoa em nome da defesa de certa idéia que, ainda que verdadeira, se torna violenta porque imposta e sobreposta à experiência. 
No entanto, ainda que não queiramos, a experiência - justamente por ser mais complexa que cada um de seus fatores - nos surpreende, recoloca questões e solicita novas elaborações. Ainda que lidemos com o outro pelo politicamente correto, o drama continua a aparecer, pois as respostas nos níveis puramente ideológicos, reativo, comportamento e mental não aplacam a complexidade que a relação é. A experiência insiste em permanecer, porque embora sejamos sujeitos da experiência, não a criamos e manipulamos a bel-prazer.

É também nesse sentido que a Fenomenologia retoma a experiência em seu caráter relacional, nos ajudando a reconhecer tanto um nível ativo, em que nos posicionamos diante daquilo que encontramos, quanto um nível passivo, em que somos provocados pela presença que o mundo é para nós (MAHFoud; MASsimi, 2008). A experiência se constitui na mútua relação sujeito-mundo, além de carregar um dinamismo próprio, que podemos (e devemos) reconhecer e afirmar.

\subsection{A EXPERIÊNCIA DO RELACIONAMENTO INTER-RELIGIOSO NA CULTURA BRASILEIRA}

No âmbito do encontro inter-religioso, esse dinamismo se mostra em sua potência, porque a estrutura mesma da experiência de encontro implica resposta pessoal à provocação de uma alteridade que instaura uma novidade. Está aqui a possibilidade de compreensão de um posicionamento humano de abertura nãoalienante.

Sanchis $(2008,2012)$ reconhece nesse movimento de abertura à alteridade um dos traços característicos da cultura dita brasileira. Não como um sistema fechado que constitui a totalidade do que seja o povo brasileiro, mas como um "princípio de organização", uma "disposição dominante" que dá direção a um processo (ainda que este possa estar acompanhado por outras direções, mesmo que opostas).

Segundo Sanchis (1995, 1997a, 2001), o pluralismo, característica tipicamente moderna, mostra-se presente desde a "descoberta" do Brasil, configurando sua sócio-gênese. A convivência entre diferentes é uma marca constitutiva deste país (ainda que atualmente esteja mais intensificada): primeiramente entre os povos (e suas respectivas religiões) indígena, europeu e africano, e depois entre os demais que aqui foram se enraizando. Encontro desigual e por vezes violento, é verdade, mas igualmente permeado por combinações, cruzamentos, contaminações, articulações, reafirmações, que foram dando ao Brasil um rosto "sincrético".

Sincretismo aqui não significa necessariamente mistura, mas sim tendência a reelaborar a própria identidade (e o universo do qual ela faz parte) no confronto com a alteridade (SANCHIS, 1994, 2012). Se por um lado, o sincretismo abarca 
processos de relativa fluidez e porosidade de identidades, por outro, inclui manifestações de afirmação clara e bem definida de identidade, em contraste com as demais. O ponto é que o "outro", de uma forma ou de outra, aparece como desafio a ser elaborado, ainda que não haja mudança radical de identidade.

Portanto, do ponto de vista sociocultural, a realidade brasileira é composta por uma estrutura sincrética que solicita os sujeitos a reelaborarem cotidianamente a própria identidade religiosa no impacto e na relação com perspectivas religiosas diferentes. Embora os riscos do fechamento e da subjugação estejam existencialmente presentes, a possibilidade de abertura à diversidade também se apresenta como uma constante da cultura brasileira. Não é por acaso que encontramos no Brasil experiências de encontro inter-religioso bem-sucedidas: há um contexto facilitador que possibilita que elas se dêem.

\subsection{A CONSTITUIÇÃO DA EXPERIÊNCIA DE ENCONTRO INTER-RELIGIOSO}

No entanto, retomando o caráter relacional da experiência, não basta ser formado numa cultura em que o diferente esteja presente, é preciso também uma tomada de posição que se deixe tocar pelo encontro, que acolha o outro em sua humanidade própria e aceite a provocação que ele é.

Uma característica fundamental do encontro é que o sujeito, por si mesmo, não é capaz de produzi-lo nem de controlá-lo: o encontro acontece. Está no acontecimento a força de provocação do encontro (GUARDINI, 2002; ROMANO, 2008). É claro que há momentos propícios que facilitem com que ele se dê, mas o fato de ele se dar é um acontecimento, está para além dos fatores que o compõem. (ROMANO, 2008).

Na verdade, o acontecimento não se reduz de forma alguma à sua atualização como fato. Ele transborda todo fato e toda atualização em virtude do conjunto de possibilidades que retém em si e, por isso, ele toca as fundações mesmas do mundo para o existente. $\mathrm{O}$ acontecimento não realiza somente uma possibilidade prévia, pré-esboçada no horizonte de nosso mundo circundante; ele alcança a possibilidade em sua raiz e, portanto, transborda o mundo inteiro daquele a quem sobrevém: não é esta ou aquela possibilidade, é a "face do possível", a "face do mundo" que aparece para ele modificada. Ou, para dizer isso de outro modo, um acontecimento não altera somente certas possibilidades no interior de um horizonte mundano que permaneceria, como tal, inalterado; na verdade, ao transbordar certas possibilidades, reconfigura o possível em sua totalidade (ROMANO, 2008, p. 42-3, tradução nossa). 3

\footnotetext{
3 En verdad, el acontecimiento no se reduce de ninguna forma a su actualización como hecho; desborda todo hecho y toda actualización por la carga de posibles que mantiene em reserva y en virtud de la cual lo que toca son los cimientos mismos del mundo para el existente. No realiza solamente un posible previo, pré-esbozado en el horizonte de nuestro mundo circundante; alcanza lo posible en su raíz y, por consiguiente, trastorna el mundo entero de aquel a quien sobreviene: no es tal o cual posible, es la "cara de lo posible", la "cara Del
} 
Romano (2008) nos ajuda a apreender o encontro como totalidade originária, como o emergir de uma novidade que solicita a quem está envolvido, transformando uma simples co-existência em relacionamento recíproco. $\mathrm{O}$ encontro é sempre novo (mesmo que seja com a situação de sempre), pois emerge dentro de um horizonte diferente de significado, e criativo, pois nos abre para algo que transcende o que está estabelecido.

Apropriando-se da fenomenologia husserliana, Di Martino (2008) descreve como, no encontro com uma humanidade diversa, somos surpreendidos por valores, costumes, objetos, símbolos, que, num primeiro momento, desconhecemos. Diante dessa surpresa, podemos ficar no nível imediato, reafirmando aquela estranheza. No entanto, reconhecemos também na própria experiência que aquela estranheza não é compartilhada por quem vive naquele mundo que nos é estranho. Podemos nos dar conta de que eles vivem aquele mundo significativamente e colhem sentido onde, a princípio, não apreendemos, e eles também podem se dar conta de que somos estranhos àquele mundo que lhes é natural. Assim, embora não compreendamos as modalidades específicas de relação daquele mundo, os compreendemos e compreendemo-nos uns aos outros como seres humanos que vivem um mundo. É este juízo calcado numa abertura recíproca a base sob a qual pode se estruturar um relacionamento em que podemos compreender aquelas modalidades específicas em sua manifestação própria e em seu caráter propriamente humano. Nas palavras de Di Martino (2008):

Tudo o que ainda é estranho, ainda incompreensível, possui um núcleo compreensível, sem o qual não poderia ser experimentado de fato, nem mesmo como estranho. Existe um limiar comum que permite compreender "uns aos outros como seres humanos". O que nos constrange a admitir esse núcleo comum? O fato incontrovertido de que, ainda que partindo de distâncias abissais, a possibilidade da compreensão é sempre aberta, e é somente a partir dela que podemos nos dar conta do incompreensível, da ignorância, do equívoco (p. 92, tradução nossa, grifos do autor). ${ }^{4}$

mundo" que aparece para él cambiada. O, para decirlo de otro modo, un acontecimiento no modifica solamente ciertas posibilidades en el interior de un horizonte mundano que permanecería, como tal, incambiado; al trastornar ciertos posibles, reconfigura, em realidad, lo posible en su totalidad.

4 Tutto ciò che è ancora cosi estraneo, ancora così incomprensibile, ha dunque un nucleo della comprensibilità, senza del quale non potrebbe essere esperito affatto, neppure come estraneo. Vi è una soglia accomunante che permette di comprenderci "gli uni gli altri in quanto uomini". Che cosa costringe ad ammettere tale nucleo comune? Il fatto incontrovertibile che, anche a partire da abissali distanze, la possibilità della comprensione è sempre aperta, ed è solo a partire da essa che si può rendere ragione dell'incomprensione, del misconoscimento, dell'equivoco. 
A consideração desse centro compartilhado e estruturalmente aberto seria o início da caminhada rumo à articulação entre vivência profunda da própria religiosidade e reconhecimento do outro como simultaneamente diferente e semelhante (Ales Bello, 1998; Berger; LuCKMANN, 2004; Di MARTINo, 2008; SOdRÉ, 2003 e 2005).

Tal apreensão da religiosidade vinculada a uma experiência de abertura pode fundamentalistas, estabelecer um ponto de crítica em relação à violência e às posições pois elas se fixam em determinados valores e concepções do que seja o mundo e a divindade, fechando-se à provocação de abertura própria da experiência que emerge no impacto com o real. Mesmo a percepção vivida - e não abstratamente identificada - da violência enquanto violência, isto é, enquanto uma atitude que fere a nossa humanidade indica a evidência presente de que algo fundamentalmente importante não está sendo adequadamente realizado, o que solicita uma elaboração sobre o que precisa acontecer, de fato, que realize aquilo que radicalmente esperamos.

É nesse sentido que Di Martino (2008) afirma que a experiência de encontro inter-religioso pode ser ocasião de problematizar o que é encontrado. Tal problematização provoca uma reconfiguração da própria consciência na medida em que esta é solicitada a elaborar o que era óbvio na experiência e a questionar se os próprios valores são frutos apenas do hábito ou vinculam-se à estrutura humana. Até a "preservação" da própria posição religiosa diante do diferente adquire um significado diverso, uma vez que se trata de uma opção e um juízo que reafirma, com vivacidade e clareza de correspondência, aquele valor a ser mantido. Uma reafirmação não necessariamente fechada, pois o que se coloca em jogo é a realização humana que se dá na diferença e com o diferente. Nesse sentido, a experiência de encontro abre uma possibilidade tanto de autocrítica quanto de adesão mais profunda à própria tradição.

Falar de "interação" não significa projetar uma modalidade de sincretismo mundial ou de globalização de sentido, que terminaria por se traduzir em uma nova modalidade de hegemonia e universalização forçada, mas significa, de um lado, afirmar que a emergência da estrutura universal da experiência não implica em prejuízo para as culturas particulares - como se se devesse proceder por subtração, abstraindo cada uma de sua concretude - e, de outro lado, e justamente em virtude desse primeiro, [significa] reconhecer que as culturas e as religiões são essencialmente confrontáveis. Se há interação, há confrontabilidade, por isso possibilidade (e mesmo dever) de crítica, mesmo que isso não possa ser feito de acordo com cânones preestabelecidos (DI MARTINO, 2008. p. 97, tradução nossa e grifos do autor). 5

\footnotetext{
5 Parlare di "interazione" non significa allora progettare una sorta di sincretismo mondiale o di globalizzazione del senso, che finirebbe con il tradursi in una nuova forma di egemonia, di universalizzazione forzata, bensì da una parte affermare che l'emergenza dell'universale struttura dell'esperienza non avviene a spese delle culture particolari - come se si dovesse procedere per sottrazione, astraendo dalla loro concretezza -, ma grazie a esse,
} 
Portanto, a possibilidade de comparação e crítica não está no nível do modelo, mas da apreensão de uma disposição original do humano, que constitui o "rosto profundo de cada subjetividade”, nas palavras de Di Martino (2008, p. 98). Deste modo, na experiência de encontro inter-religioso, podemos apreender tanto a manifestação própria de cada posição quanto este princípio crítico que se realiza na manifestação, mas não é redutível a ela. O homem vive na história e na cultura, mas não totalmente definido pela condição histórico-cultural na qual se encontra, já que é capaz de se "distanciar" daquela realidade perguntando pelo sentido e abrindo novas possibilidades a partir de um critério imanente que transcende o que está estabelecido.

Esta capacidade de se perguntar e, por conseqüência, de verificar cada experiência vivida dizendo "corresponde" ou "não corresponde" não é somente ineliminável, mas irrenunciável para quem pretenda ser humano (GIUSSANI, 2009). Portanto, o reconhecimento de um núcleo comum originalmente aberto que estrutura a experiência é condição para que se compreendam os efetivos diálogos em curso com o diferente a partir de uma consciência continuamente renovada da própria posição (Di MARTINO, 2008; SODRÉ, 2005).

2 O ENCONTRO ENQUANTO RELAÇÃO SOCIAL

Embora seja evidente que o encontro inter-religioso se constitua na relação social, muitas vezes não nos damos conta do real significado dessa constituição. Por um lado, reduzimos a relação inter-religiosa a determinado modo de organização social objetivada que garanta a boa convivência entre pessoas e instituições religiosas diversas. Por outro, subjetivamos a relação inter-religiosa como se ela fosse fruto única e exclusivamente da interação individual entre os sujeitos envolvidos.

A Sociologia Relacional, tal como proposta por Donati (1991, 2006, 2009, 2010), nos oferece importante contribuição justamente por retomar o significado profundo e o valor da relação social, problematizando a constituição relacional de todo fenômeno humano, inclusive do encontro inter-religioso, compreendido enquanto fenômeno psicossocial.

Donati (2006) nos convida a adotar uma lógica relacional não só no modo de observar a realidade como também na maneira de analisá-la. Essa lógica abre caminho para conhecermos o encontro inter-religioso na relação entre a nossa

e dall'altra riconoscere che le culture e le religioni sono essenzialmente confrontabili. Se vi è interazione, vi è confrontabilità, perciò possibilità e anche dovere della critica, anche se ciò può non avvenire secondo canoni prestabiliti. 
observação (a partir de um ponto de vista) e o "fato" social observado. Em síntese, é um chamado a pensar por e através das relações.

No entanto, isso não significa assumir uma posição relativista - no sentido de definirmos, pelo nosso ponto de vista, a totalidade do que seja o encontro interreligioso - pois a observação é sempre relacional. O próprio relacionamento entre pessoas de religiões diferentes nos provoca de certo modo, indica direções possíveis e abre perspectivas de observação a partir das quais o analisaremos e compreenderemos. Não é possível uma observação justa que desconsidere, por exemplo, a tomada de posição dos sujeitos envolvidos no encontro inter-religioso ou o contexto sociocultural que facilita com que o encontro aconteça.

E quais seriam as características constitutivas da relação que brota da experiência de encontro inter-religioso? Donati (2009) destaca alguns fatores que a constituem (como os meios, metas, normas e valores), com o cuidado de apontar que nenhum destes fatores, por si, esgota ou reifica a complexidade da relação mesma. É preciso apreender a relacionalidade que emerge entre os elementos que compõem a relação social. Nesse sentido, o encontro inter-religioso é uma relação que, a um só tempo, acontece num meio social que o condiciona de certo modo, apresenta determinadas normas e metas próprias daquela relação, expressa alguns valores compartilhados.

De modo sintético, Ruiz (2006) oferece uma definição que nos permite aprofundar na dinâmica própria de toda relação social, considerando-a como "efeito emergente de um curso de ação recíproca condicionada por um contexto intencional (ou seja, por valores e metas presentes neste curso de ação) e estrutural (ou seja, pelas normas e meios disponíveis para aqueles que atuam)" (p. 24). O encontro inter-religioso, como efeito emergente, não é definível à priori, seja pelos sujeitos que se encontram (e por suas respectivas filiações religiosas), seja pela situação em que se encontram. Há um contexto relacional que oferece condições de possibilidade para a tomada de posição de cada sujeito no impacto e na elaboração da presença do outro.

É nesse sentido que Donati (2009) destaca que a relação mesma possui uma realidade própria que se constitui como meio que conecta ação social (subjetividade e intersubjetividade) e sistema social (estrutura objetiva e objetivada). Utilizando-se de uma metáfora, Donati (2009) delimita a relação como a "molécula do social", não sendo possível, portanto, apreender a complexidade do encontro inter-religioso eliminando qualquer um de seus elementos constituintes ou tomando um desses elementos como definidores da totalidade daquela estrutura molecular. O modo e a incidência de cada um desses elementos variam conforme a 
relação se desenvolve. Daí a importância de uma análise concreta que colha o impacto e as conseqüências do encontro inter-religioso, uma vez que o modo como a relação se estrutura - e se institucionaliza ou não - e o grau de reciprocidade dos sujeitos (individuais ou coletivos) em interação variam conforme o desenrolar da própria relação (DONATI, 1991, 2009).

O encontro inter-religioso não se dá num vazio: ele é condicionado pelo contexto mais amplo no qual está inserido, que pode facilitar ou não a sua concretização. Como resposta para essa questão, vimos como multiculturalismo emergiu como um modelo que busca oferecer um contexto favorável para administrar o relacionamento com o diferente como afirmação das identidades. No entanto, Donati (2010) alerta que esse modelo se mostra frágil justamente porque propõe uma teoria redutiva da relação social (e, portanto, do reconhecimento recíproco), pois falta um modus vivendi que dê conta do relacionamento que emerge entre as culturas e as religiões a partir do reconhecimento de certos critérios humanamente compartilhados.

Além disso, não basta que o contexto social seja favorável ao encontro: é preciso que os sujeitos se posicionem diante daquela relação vivida, afirmando o que emerge dali e dando um direcionamento ao curso da própria relação. Mas não é qualquer posicionamento que realiza a relação de encontro inter-religioso em sua plenitude.

Donati (2010) identifica duas possibilidades redutivas de interação. A primeira, denominada dialética, é aquela na qual o encontro se realiza na fronteira, isto é, negociam-se pactos que estabelecem abstratamente um terreno comum para manejar o relacionamento e evitar o conflito. Nessa posição, a diferença é concebida como um problema que precisa ser administrado até se encontrar um ponto comum. É a lógica do acordo, do consenso. A segunda posição é a binária, em que o encontro é tomado como espaço de conflito. A diferença é lida como inconciliável e, num certo sentido, discriminatória. O relacionamento se estabelece então como um terreno de lutas, em que cada sujeito disputa o seu espaço e o direito à sua diferença.

Estas são lógicas possíveis, mas redutivas, porque não tomam a relação como critério de elaboração. É verdade que os confins da interação podem se configurar como terreno de conflito e negociação, mas é também verdade que se trata de um terreno de pertença recíproca. A diferença (assim como a igualdade) emerge na relação, sendo esta um ponto de unidade a partir da qual as diversidades se manifestam. As identidades se constituem como modalidades diversas de viver e interpretar a relação no confronto com determinadas premissas fundamentais do gênero humano. As diferenças reais emergem no confronto e na relação com o 
outro, mas isto não significa necessariamente afastamento ou rompimento, já que é a relação que possibilita o reconhecimento da diferença e de um horizonte humano recíproco. Nesse sentido, a relação social, ao mesmo tempo em que diferencia, aproxima, permitindo a afirmação de um terreno compartilhado: a própria relação (humanamente vivida) e o bem que ela é e gera.

A diferença é um problema quando não é enquadrada ou enquadrável de modo significante, porque falta um contexto relacional de reconhecimento que forneça uma resposta à dissonância cognitiva e à ferida que ela coloca. A razão relacional diz que o aspecto expressivo (cultural) e o relacional (a sociedade) não são separados, mas concretamente interconectados. A cultura vive na relação social, e não fora dela. Se a diferença percebida se torna um problema, é porque o compartilhamento que existe na relação não emerge antes de perceber a diferença, mas somente depois dessa (DONATI, 2010. p. XI, tradução nossa). ${ }^{6}$

O relacionamento que nasce do encontro inter-religioso pode então se tornar um bem na medida em que possibilita o reconhecimento e a transformação recíproca. E Donati (2010) aponta ainda que não se trata de reconhecer o outro somente no nível do discurso (como uma conversa sobre determinado assunto) ou mesmo da tolerância funcional (na qual cada um tem o seu espaço para se manifestar). $\mathrm{O}$ verdadeiro reconhecimento parte da interação entre os sujeitos envolvidos e nasce dentro de uma relação social concreta. É na relação que podemos nos dar conta não só da identidade do outro, mas também da verdade que ele comunica e da presença que ele é.

O fato mesmo do outro ser é um acontecimento dado na relação que abre questões que não estavam colocadas, solicita elaborações que não seriam realizadas individualmente, possibilita a percepção de proximidades que a princípio seriam impensadas. A presença do outro é vivida e elaborada como um dom que desperta gratidão e comunhão. E a relação mesma gera bens que passam a ser vividos e almejados.

É nessa radicalidade de reconhecimento relacional que o encontro e o diálogo podem efetivamente frutificar, uma vez que a diferença é vivida dentro de um horizonte de significado humanamente compartilhado, podendo gerar elaboração da própria identidade, afirmação dos valores fundamentais e transformação dos sujeitos envolvidos. Isso não significa relativismo e aceitação de toda manifestação e de qualquer diferença, já que a própria relação emerge como critério para avaliar

\footnotetext{
${ }^{6}$ La differenza fa problema quando non sia inquadrata o inquadrabile in modo significante, perché manca un contesto relazionale di riconoscimento che fornisca una risposta alla dissonanza cognitiva e alle sfide che essa pone. La ragione relazionale viene a dirci che l'aspetto espressivo (culturale) e quello relazionale (la società) non sono separati, ma concretamente sempre interconnessi. La cultura vive nella relazione sociale, non fuori di essa. Se la differenza percepita fa problema, è perché la comunanza, che esiste nella relazione, non emerge prima del sentire la differenza, ma solo dopo di essa.
} 
se os posicionamentos realizam ou não a plenitude da relação e da humanidade que ela busca expressar.

$\mathrm{Na}$ realidade brasileira temos ocasião de presenciar essa dinâmica em ato, já que a relação é fator fundamental que permite a aproximação e a convivência salutar entre perspectivas diferentes. Não é incomum encontrarmos - nem nos estranha coletivamente -, por exemplo, casais ou grandes amigos que professam religiões diferentes. Isso não significa que não haja tensões. O ponto é que a relação que há entre os sujeitos envolvidos é uma base sustentadora que facilita inclusive que as diferenças sejam vividas e elaboradas no momento mesmo em que elas emergem.

Para tanto, não basta viver uma relação, é preciso tomá-la de modo reflexivo, explicitando as razões que a sustentam e afirmando a presença transformadora que ela é. Donati (2010) denomina essa atitude como reflexividade relacional, processo em que os sujeitos (individuais ou coletivos) elaboram a própria posição a partir do relacionamento que emerge entre eles. Tal elaboração se volta tanto para os sujeitos envolvidos quanto para a própria relação como objeto de reflexão. Como vimos, o encontro acontece, e é a elaboração desse acontecimento que permite o emergir da novidade $d a$ relação na relação, e não da auto-afirmação da própria posição diante do outro.

É nesse sentido que Donati (2010) defende que, para sustentar relacionamento intercultural e inter-religioso calcado nos direitos humanos, é fundamental adotar um paradigma relacional capaz de ver e articular as razões que formam o interhumano, aquilo que acontece entre os sujeitos. Além disso, o autor aponta também a importância de se estimular a reflexividade interna de cada cultura e religião a partir da criação de interfaces relacionais com perspectivas diferentes, o que promove uma abertura social facilitando o caminho para a elaboração dos sujeitos em interação.

\section{CONCLUSÃO}

Seja pela via da experiência, seja pela via da relação social, o encontro interreligioso emerge como um fenômeno que solicita pessoalmente e coletivamente a quem se dispõe a vivenciá-lo. O desafio da convivência está muito mais em se dispor a essa provocação do encontro do que em propor modelos politicamente corretos para administrar o drama da diferença.

Tanto o olhar para a experiência quanto para a relação social coloca em jogo a centralidade constitutiva da mútua relacionalidade sujeito-mundo. Somos o que somos porque o mundo nos provoca de certo modo, e o mundo é o que é porque o co-construímos quando respondemos pessoal e socialmente 
à provocação que ele nos coloca.

Essa mútua co-constituição recoloca o drama da convivência inter-religiosa em outros termos, já que a percepção e a elaboração dos sujeitos envolvidos nascem da relação estrutural que há entre eles. Em outras palavras, é a relação mesma que define, em parte, o modo como o outro é percebido e elaborado. Por mais óbvio que possa parecer, não há convivência salutar sem relacionamento.

Um dos erros do multiculturalismo é justamente buscar criar um espaço em que todos os sujeitos sejam afirmados em sua diferença sem considerar nem propiciar que estes se relacionem entre si. E uma das possibilidades da cultura brasileira é justamente poder se estruturar a partir de elaborações abertas do relacionamento existente com o diferente.

Além disso, é por meio da verificação da ressonância dessa relação na experiência que a elaboração do encontro com o diferente se torna vitalizada. Se a relação se desvincula da experiência, ela se torna abstrata, e o encontro perde sua força de mobilização pessoal e coletiva.

No entanto, como vimos, não é qualquer modalidade de convivência que atualiza a relação propriamente humana em sua plenitude, assim como não é qualquer elaboração do vivido que se torna efetivamente experiência. Antes de ser, ou melhor, justamente por ser um encontro entre diferentes é um encontro entre humanidades, o que explicita a radicalidade de um olhar que colha quais são os fatores constitutivos que possibilitam que o humano seja.

A diferença só é percebida enquanto diferença porque é, primeiramente, reconhecida como humana (ou desumana, caso esta diferença não realize quem o homem é). Giussani e o referencial fenomenológico reconhecem na dinâmica própria da experiência certos critérios que são elementares, fundantes, que formam a nossa humanidade. Donati apreende um terreno humanamente compartilhado que emerge como bens relacionais a serem vividos, estimulados e defendidos pessoal e socialmente. Ambas as perspectivas, cada qual a seu modo, explicitam a centralidade de um núcleo constitutivo de toda humanidade, estruturalmente aberto, que emerge e acontece a partir do impacto com o real.

Desse modo, não é o homem que estabelece a própria medida: é a provocação do real que desperta o dinamismo propriamente humano. Cabe ao homem reconhecer, acolher, afirmar e desenvolver o que lhe corresponde nesse impacto. Não é por acaso que tanto Giussani e a Fenomenologia quanto a Sociologia Relacional criticam o relativismo e o multiculturalismo que dele surgiu porque desconsideram um critério humano compartilhado a partir do qual é possível avaliar a diferença. Há um ponto de unidade na diferença que possibilita que o encontro com o 
outro enquanto outro seja ocasião de transformação e de enriquecimento recíproco.

Nesse sentido, o Brasil tem uma importante contribuição para o mundo já que mostra possibilidades concretas de relacionamento entre perspectivas diferentes em que o humano está contemplado. Esse descentramento ressalta a importância do encontro com o diferente como formador da pessoa, da sociedade e da cultura, já que é por meio do encontro que estas efetivamente se realizam enquanto tal.

\section{REFERÊNCIAS}

ALES BELLO, A. Culturas e religiões: uma leitura fenomenológica (A. Angonese, trad.). Bauru, SP: Edusc, 1998.

BERGER, P; LUCKMANN, T. Modernidade, pluralismo e crise de sentido: a orientação do homem no mundo moderno. Tradução de Edgar Orth. Petrópolis, RJ: Vozes, 2004 .

COLOMBO, E. Convertire i musulmani: L'esperienza di un gesuita spagnolo del Seicento. Milano: Bruno Mondadori, 2007.

DI MARTINO, C. L'incontro e l'emergenza dell'umano. In: PRADES, J (Org.). All'origine della diversità: le sfide del muticulturalismo. Milano: Guerini, 2008. p. 85-103.

DONATI, P. Introduzione alla sociologia relazionale. Milano: Franco Angeli, 1991.

DONATI, P. L'analisi relazionale: regole, quadro metodologico, esempi. In: DONATI, P (Org.). Sociologia: una introduzione della società. Padova: CEDAM, 2006. p. 195-251

DONATI, P. Teoria relazionale della società: i concetti di base. Milano: Franco Angeli, 2009.

DONATI, P. Oltre il multiculturalismo: la ragione relazionale per un mondo comune. Roma: Laterza, 2010.

GASPAR, Y. E.; MAHFOUD, M. Uma leitura histórica do conceito de experiência e uma proposta de compreensão do ser humano em seu caráter essencial: experiência elementar e suas implicações para a psicologia. In: Anais do III Seminário Internacional de Pesquisa Qualitativa e V Encontro de Fenomenologia e Análise do Existir. São Bernardo do Campo São Paulo, 2006. Disponível em: <www.sepq.org.br/IIIsipeq/anais/pdfs/pchf11.pdf>. Acesso em: 20 jun. 2013.

GIUSSANI, L. O senso religioso. Tradução de P. A. Oliveira. Brasília: Universa, 2009.

GUARDINI, R. O encontro . Trad de J. Peres. In: COGO, L.; CHAVES C. C. (Orgs.) Curso de Extensão em Educação Infantil. Belo Horizonte: AVSI, 2002. p. 204-212.

HALL, S. A identidade cultural na pós-modernidade. 11. ed. Tradução de Tomás Tadeu da Silva e Guacira Lopes Louro. Rio de Janeiro: DP\&A, 2006.

HUSSERL, E. Idéias para uma fenomenologia pura e para uma filosofia 
fenomenológica. Tradução de Márcio Suzuki. Aparecida, SP: Idéias e Letras, 2006.

HUSSERL, E. A crise das ciências européias e a fenomenologia transcendental: uma introdução à Filosofia Fenomenológica. Tradução de Dennis Ferrer. São Paulo:

Forense Universitária, 2012.

MAHFOUD, M, MASSIMI, M. A pessoa como sujeito da experiência: contribuições da fenomenologia. Memorandum, Belo Horizonte/Ribeirão Preto, v. 14, p. 52-61, 2008. Disponível em:

<http://www.fafich.ufmg.br/memorandum/a14/mahfoudmassimio2.htm>. Acesso em: 20 set. 2010.

MAHFOUD, M. Experiência elementar em psicologia: aprendendo a reconhecer. Brasília: Universa, 2012.

ROMANO, C. Lo posible y el acontecimiento. Tradução de Aníbal Fornari, Patricio Mena e Enoc Muñoz. Chile: Ediciones Universidad Alberto Hurtado, 2008.

RUIZ, P. Estudio introductório. In: DONATI, P. Repensar la sociedad: el enfoque relacional. Madrid: EIU, 2006. p. 09-47

SANCHIS, P. Para não dizer que não falei de sincretismo. Comunicações do ISER, Rio de Janeiro, v. 13, p. 4-11, 1994.

SANCHIS, P. As tramas sincréticas da história. Revista Brasileira de Ciências Sociais, São Paulo, v. 28, p. 123-138, 1995.

SANCHIS, P. O campo religioso contemporâneo no Brasil. In: ORO, P.; STEIL, C. (Orgs.) Globalização e religião. Petrópolis, RJ: Vozes, 1997. p. 103-115.

SANCHIS, P. Religiões, Religião... alguns problemas do sincretismo no campo religioso brasileiro. In: SANCHIS, P (Org.). Fiéis e cidadãos: percursos de sincretismo no Brasil. Rio de Janeiro: Eduerj, 2001. p. 9-58.

SANCHIS, P. Cultura brasileira e religião: passado e atualidade. Cadernos Ceru (USP), São Paulo, v. 19, p. 71-92, 2008.

SANCHIS, P. O “som Brasil”: uma tessitura sincrética? In: MASSIMI, M. (Org.).

Psicologia, Cultura e História: perspectivas em diálogo. Rio de Janeiro: Outras Letras, 2012. p. 15-54

SANTOS, B. S. Os processos da globalização. In: SANTOS, B. S. (Org.). A globalização e as ciências sociais. São Paulo: Cortez, 2002. p. 25-102.

SCOLA, A. Prefazione. In: PRADES, J. (Org.). All'origine della diversità: le sfide del muticulturalismo. Milano: Guerini, 2008. p. 9-11.

SEMPRINI, A. Multiculturalismo. Tradução de Laureano Pelegrin. Bauru, SP: EDUSC, 1999.

SODRÉ, O. Globalização e Pluralismo: guerra e violência ou paz e diálogo. In: PEREIRA M. S.; SANTOS, L. A. (Orgs.). Religião e violência em tempos de globalização. São 
Paulo: Paulinas, 2004. p. 11-52.

SODRÉ, O. Monges em diálogo a caminho do Absoluto: estudo psicossocial do diálogo inter-religioso monástico. Rio de Janeiro, 2005. 270 f. Tese (Doutorado em Psicologia). Programa de Pós-Graduação em Psicologia Clínica, Pontifícia Universidade Católica do Rio de Janeiro.

STEIN, E. Estructura de la persona humana. Tradução de F. J. Sancho e col. In: STEIN, E. Obras completas v. IV: escritos antropológicos y pedagógicos. Vitoria, Espanha: El Carmen, 2003. p. 555-749.

STEIN, E. Contribuiciones a la fundamentación filosófica de la psicología y de las ciencias del espíritu. Tradução de F. J. Sancho e col. In: STEIN, E. Obras completas, v. II: escritos filosóficos (etapa fenomenológica: 1915-1920). Burgos, Espanha: Monte Carmelo, 2005. p. 207-520.

TOURAINE, A. O sujeito. Tradução de Jaime A. Clasen e Ephraim F. Alves. In: Poderemos viver juntos?: iguais e diferentes. Petrópolis, RJ: Vozes, 1999. p. 68-111.

WARNIER, J. P. A mundialização da cultura. 2. ed. Tradução de Viviane Ribeiro. Bauru, SP: EDUSC, 2003. 